\title{
Necesidades de información y comportamiento informativo de los agricultores de agave azul de Tequila, Jalisco: un estudio de caso
}

\author{
Armando Sánchez Soto *
}

Artículo recibido:

28 de agosto de 2014.

Artículo aceptado:

14 de mayo de 2015.

\section{RESUMEN}

En este artículo se presenta un análisis sobre las necesidades de información y el comportamiento informativo que muestran los agricultores de agave azul del municipio de Tequila, Jalisco. Actualmente existen diferentes grupos de agaveros — como también se les conoce a esta clase de agricultores- que se distinguen por elementos característicos como la tenencia de la tierra, su poder adquisitivo y su estatus social. Destacan los agricultores independientes y los agricultores que alquilan sus parcelas, grupos de población en los que se enfocó la investigación De acuerdo con los resultados del estudio, tanto sus necesidades de información como la consulta de determinadas fuentes y

* Instituto de Investigaciones Bibliotecológicas y de la Información de la UNAM, México. armando@iibi.unam.mx

INVESTIGACIÓN BIBLIOTECOLÓGICA, Vol.30, Núm.69, mayo/agosto, 2016, México, ISSN: 0187-358X. pp. 143-178 
recursos informativos para satisfacerlas giran en torno a sus actividades agrícolas y al desarrollo de su vida cotidiana.

Palabras clave: Agaveros; Agricultores de Agave Azul; Comportamiento Informativo; Fuentes de Información; Necesidades de Información; Recursos Informativos.

\section{Abstract \\ Information needs and information behavior of blue agave farmers in Tequila, Jalisco: A case study \\ Armando Sánchez-Soto}

This article presents an analysis of information needs and information behavior of blue agave farmers in the municipality of Tequila, Jalisco (Mexico). Nowadays we can find many different kinds of agaveros —as these farmers are commonly called in Mexico- who are classified by some characteristic features, such as property holdings, economic power, social status, and others. There are two main groups of agaveros, the independent farmers and those who rent out land for others to cultivate. Findings show that the information needs of blue agave farmers and the information resources they consult are associated with their farming activities and daily lives.

Keywords: agaveros; blue agave farmers; information behavior; information needs; information source; information resource.

\section{INTRODUCCIÓN}

$\mathrm{E}^{\mathrm{I}}$ cultivo del maguey tequilero, conocido también como agave azul o Agave tequilana weber (nombre científico de esta planta), es la especie más utilizada como materia prima para la obtención del tequila en la región centro del estado de Jalisco, principalmente en los municipios de Tequila, Amatitán y El Arenal. 
Actualmente, las prácticas agrícolas empleadas en el cultivo del agave azul son las mismas que se realizaban desde tiempos prehispánicos. No obstante, con el paso del tiempo se han incorporado nuevas y novedosas técnicas como resultado del avance tecnológico y científico aplicado a la producción agrícola en general. La mayor parte de estas tecnologías comenzaron a utilizarse a partir del llamado boom tequilero de 1996, cuando, como nunca antes, se vendió y exportó tequila en México y el resto del mundo, situación que a su vez provocó una crisis de sobrexplotación del agave. Debido a lo anterior, se incrementó el interés por el conocimiento del agave azul y su cultivo en el territorio mexicano (principalmente en las regiones de Jalisco mencionadas) y se desarrollaron diversas investigaciones, la mayoría de las cuales describen aspectos relacionados con la historia del cultivo de la planta, su fisiología, las técnicas para su cultivo y producción, las enfermedades y plagas que la afectan y, por supuesto, su importancia dentro de la industria del tequila.

Asimismo, se desarrollaron distintas expresiones artísticas, culturales, académicas y sociales en torno a los elementos que componen la cadena productiva agave-tequila, en particular sobre el paisaje agavero, las antiguas fábricas de tequila, la actual industria tequilera de reconocidas marcas y, más recientemente, un elemento considerado como insigne dentro de este contexto: el jimador. Sin embargo, hasta el momento, el elemento básico y primordial que da origen a dicha cadena, el agricultor de agave azul, ha sido prácticamente olvidado. ${ }^{1}$

La mayor parte de las investigaciones relacionadas con la producción del tequila mencionan al agricultor de agave azul de forma indirecta y aislada; normalmente lo hacen en relación con aspectos históricos de las grandes casas tequileras, o bien, con movimientos sociopolíticos como la Revolución mexicana o el reparto agrario, pero en ningún estudio se hace referencia a su actividad como agricultores, su estilo de vida, su idiosincrasia, y mucho menos a sus necesidades de información y su comportamiento informativo.

Ubicar este vacío de información acerca de los agricultores de agave azul es precisamente lo que confiere relevancia al desarrollo de la presente investigación, particularmente al considerar que hasta el momento se desconoce cuáles son las fuentes y recursos a los que dicha población acude para satisfacer las necesidades de información derivadas de su trabajo y del diario acontecer de sus vidas. Este propósito surge del principio científico que sugiere estudiar las necesidades de información y el comportamiento informativo de

1 Incluso, durante mucho tiempo se pensó que esta planta se desarrollaba por medios exclusivamente naturales, sin necesidad de algún tipo de cuidado, tratamiento o conservación de parte de persona alguna. 
comunidades no académicas, que hasta ahora han sido relativamente ignoradas, en particular aquellas relacionadas con el sector agrícola mexicano.

El reporte de esta investigación está dividido en cinco partes principales. En la primera se incluyen algunos antecedentes y referencias a investigaciones previas relacionadas con el tema, que sirven como base de conocimiento; en la segunda se esboza el estado actual que guardan los agricultores de agave azul de Tequila, Jalisco, en relación con su labor agrícola, estilo de vida e idiosincrasia; en la tercera se detalla la metodología utilizada en la investigación; en la cuarta se presenta el análisis de los resultados obtenidos y, finalmente, en el quinto apartado se ofrecen algunas conclusiones generales.

\section{Antecedentes}

La primera investigación relacionada con las necesidades de información y el comportamiento informativo de agricultores fue realizada en 1985 en Nigeria por Lenrie O. Aina, quien determinó que los tópicos más importantes de los cuales este grupo de personas necesitan información son "técnicas de riego, técnicas de fertilización, equipo para el trabajo de arado, cultivo y cosecha, estado del tiempo, clima, meteorología, técnicas de cultivo según la especie de plantas, control de plagas y pesticidas" (Aina, 1985: 38). Posteriormente, Nason (2007: 20) menciona al respecto lo siguiente:

[...] los agricultores en el desarrollo de las naciones tienen necesidades similares a las de sus colegas norteamericanos como son el tipo de suelo de los campos de cultivo, el clima y la necesidad de acceder a la tecnología agrícola, así como la obtención de créditos y el mercado de precios.

Los recursos a los que recurren los granjeros, según Nason (2007: 22), son "fuentes electrónicas [Plants, Agrícola, entre otras], radio y televisión, publicaciones para granjeros y agricultores, bibliotecas, servicios cooperativos, estaciones experimentales”.

Por otra parte, en el año 2010, el grupo de interés de las bibliotecas de agricultura de la Federación Internacional de Asociaciones e Instituciones Bibliotecarias (IFLA), en conjunto con la Asociación Internacional de Especialistas de Información Agrícola (IAALD), establece que las necesidades de información de los agricultores giran en torno a los temas de fertilidad y erosión de los suelos, condiciones climáticas, fertilizantes, plagas, control de las malas hierbas, gestión del agua, créditos agrícolas, qué hacer después de las cosechas, transportes, marketing, entre otras (IFLA, 2010). 
En México, entre los años 2009 y 2014 se realizaron cuatro tesis de maestría y una de doctorado en el Posgrado de Bibliotecología y Estudios de la Información, todas ellas relacionadas con las necesidades de información de agricultores de la industria vitivinícola —el cultivo de la vid-, cuyos resultados se asemejan, en algunos casos, a los hallazgos obtenidos en las investigaciones anteriormente mencionadas.

\section{Los agricultores de agave azul de Tequila, Jalisco: antecedentes históricos}

\section{Los primeros agricultores de agave azul de Tequila, Jalisco}

Los primeros registros de actividad humana relacionada con el cultivo del agave azul en el estado de Jalisco datan del año 1500 a. de n. e. Los habitantes de esta región dejaron, en las llamadas tumbas de tiro, diversos elementos de su culto a los muertos, algunos de los cuales estaban relacionados con la práctica alimenticia y ritual del agave (Colunga et al., 2007). Entre las ofrendas depositadas en las tumbas se encuentran delicadas vasijas de barro bruñido, en las que se representan cuencos llenos de pencas de agave cocido o personajes transportando en sus espaldas corazones jimados del agave, también llamado mezcal. Estas imágenes son contemporáneas a las evidencias de hornos para agave localizadas en la cuenca de la laguna de Sayula, así como en las faldas del cerro de Tequila dentro de una población antiguamente llamada Teochinchán (Colunga et al., 2007) —justamente en lo que hoy se conoce como el municipio de Tequila.

La Tradición Teochinchán ${ }^{2}$ — desarrollada alrededor del volcán de Tequila y representada por una construcción de estructuras concéntricas conocidas como Guachimontones- mantuvo como parte de sus mecanismos de subsistencia una especie de monopolio comercial regional mediante la explotación del agave; con tal propósito, esta sociedad fue modificando durante siglos el entorno y la flora originarios para adaptarlos al cultivo del mezcal azul y otras variedades afines de Agave tequilana (Dansac, 2012).

De acuerdo con algunas crónicas, se cree que el primer grupo de habitantes relacionados con el cultivo prehispánico del agave azul fue el de los tiquilos, quienes comenzaron a cultivarlo con el fin de domesticarlo y obtener de él diferentes productos, entre ellos, la ya desde entonces apreciada bebida: el tequila.

2 Compleja sociedad antigua que existió probablemente desde el año 300 a. de n. e. hasta el 900 d. de n. e. en el norte de Guadalajara. 
Según José Rogelio Álvarez (1969), los tiquilos —de quienes se desprende el nombre tequila - eran una tribu de indígenas nahuatlacas que utilizaban el maguey con diferentes fines, como el uso de las pencas en la protección de sus casas, así como para la obtención de bebidas, de las que en un principio únicamente se extrajo el llamado octli poliuhqui o pulque.

En realidad, los tiquilos tardarían varios años en descubrir que de la destilación del agave podía obtenerse una bebida de mayor grado alcohólico; es probable que después de cocer el mezcal lo molieran y fermentaran, tomando el mosto en esa forma, sin llegar a destilarlo, pues es la destilación la que clarifica el líquido y lo hace más fuerte y mucho más concentrado.

\section{La influencia española en el cultivo del agave y el inicio de la producción masiva}

Ya para el siglo XVIII, mediante un proceso de producción que dejó de ser exclusivo de las comunidades indígenas de la región, la destilación del vino-mezcal —como originalmente se le conocía al tequila— quedó en manos de los españoles, quienes iniciaron una actividad productiva que lo vinculó rápidamente al resto de los productos traídos del Viejo Continente y que encontraron un importante nicho de comercialización en la Nueva España; con este primer boom de interés en el consumo de la bebida se inició también el desarrollo masivo de plantaciones agaveras en el municipio de Tequila.

Lo anterior también provocó que los antiguos agricultores del agave dejaran de tener el control de su producción para su uso y comercialización, lo cual pasó a manos de los grandes hacendados, quienes a partir de entonces determinaron los precios en la compra de los terrenos pertenecientes a los indígenas tequileños, los precios en la venta del agave por tonelada, los salarios pagados a los agricultores que contrataban para trabajar en sus haciendas y las formas de venta y exportación, entre muchos otros aspectos. Tanta fue la hegemonía de estos personajes sobre la producción de la planta que para los siglos XVII y XVIII eran ellos los que poseían los recursos económicos necesarios para desarrollar el proceso productivo, generando así el inicio de una forma de especialización de cultivo de agaves, único en la Nueva España y en el resto de América.

\section{El reparto agrario y la modernización de los agricultores de agave azul de Tequila}

Para la segunda y tercera década del siglo XX, la información relacionada con la forma de vida de los agricultores de agave azul de Tequila no es del 
todo clara; de hecho, existe mucha confusión en cuanto a cómo ésta se desarrolló con respecto a décadas anteriores. Dicha situación se debe a que con los reacomodos revolucionarios y políticos originados por el movimiento armado, el estilo de vida de los agricultores se vio radicalmente afectado, pasando de un modo de vida y trabajo meramente rural hacia uno de carácter más industrial.

Con el reparto agrario promovido durante la presidencia de Lázaro Cárdenas se rompe con un proceso regional en el que la actividad productiva se centraba en un solo grupo o dueño, en este caso el de los hacendados industriales tequileros, propietarios de las grandes fábricas. En este contexto, se empieza a hablar de un pacto social agrario, dado el trato privilegiado que el Estado otorga a los campesinos. Además de cumplir con una de las demandas más sentidas de la Revolución mexicana (el reparto de la tierra), el objetivo de tal política era lograr la asimilación de la sociedad civil rural al nuevo régimen.

En cuanto a las tierras de cultivo de dichos agaveros, el reparto agrario comprendió, además de la organización de ejidatarios y agricultores, la rotación, diversificación e introducción de nuevos cultivos, la selección de semillas, el empleo de maquinaria, el uso de fertilizantes y la creación de institutos, laboratorios y granjas experimentales. También se privilegió el aprovechamiento integral de todos los cultivos y se estimuló el desarrollo del crédito agrícola dirigido a los pequeños ejidatarios y agricultores.

\section{Los agricultores de agave azul en el siglo XXI}

De acuerdo con el último censo de población y vivienda llevado a cabo en el año 2010, el municipio de Tequila cuenta con 40697 habitantes, de los cuales $49.5 \%$ son hombres y $50.5 \%$ son mujeres. ${ }^{3}$ Los porcentajes de quienes trabajan directa o indirectamente en el cultivo del agave azul, o bien ya no lo hacen, son los siguientes: $20 \%$ trabajan de manera total, $40 \%$ alternan el cultivo con otras actividades económicamente remuneradas, $10 \%$ lo hacen de manera eventual y $30 \%$ ya no trabaja con el agave o nunca lo ha hecho.

Como puede verse, el interés por parte de los agricultores de agave azul de dicho municipio, por dedicarse exclusivamente al cultivo de la planta, ha disminuido considerablemente; este es un fenómeno derivado de una serie de acontecimientos iniciados en el año de 1996 con el surgimiento del llamado boom tequilero, situación que años más tarde influiría considerable y directamente en el delineamiento del perfil informativo de dichos agricultores. 


\section{El boom tequilero y la crisis de sobrexplotación del agave azul}

En el año de 1996, la producción de tequila dentro de la región identificada como territorio de denominación de origen del tequila ${ }^{4}$ alcanzó cifras significativamente elevadas en comparación con las décadas anteriores, no sólo dentro del país, sino incluso fuera de él. Tal como lo señalan los reportes oficiales y diversas estadísticas, para septiembre de 2012 la producción de tequila a nivel nacional se ubicó en 196.6 millones de litros. Asimismo, el índice de exportación internacional de dicha bebida alcanzó la cifra de 127.4 millones de litros. ${ }^{5}$ Como es de imaginarse, este fenómeno propició que la producción y consumo de agave azul alcanzara también cifras exorbitantes en comparación con los años anteriores.

En el año 2007, el consumo de agave azul para la elaboración del tequila alcanzó una cifra de 417000 toneladas, situación que cambió considerablemente un lustro después, ya que para septiembre de 2012 esta cantidad había aumentado a 676100 toneladas, siendo el municipio de Tequila el que produjo la mayor cantidad de ellas con aproximadamente 11000 toneladas. $^{6}$

Hoy en día, las plantaciones de agave azul dentro de la zona de denominación de origen integran un inventario de más de cuatro millones de plantas sembradas entre los años 2000 y 2006; de esta cifra aproximadamente 80000 toneladas fueron producidas en el municipio de Tequila, ${ }^{7}$ es decir, en tan sólo dos años la producción de la planta en este lugar aumentó en casi $10 \%$.

Lo anterior derivó en una serie de fenómenos, de los cuales el primero, y quizá el más considerable, fue la crisis de sobreproducción o sobrexplotación del agave.

\section{La crisis de sobrexplotación y los cambios en los sistemas de producción de los agricultores de agave azul: el surgimiento de las necesidades de información relacionadas con el entorno}

Debido a las altas ventas del tequila (hoy en día se producen alrededor de 10 millones de litros de tequila al año), la mayor parte de los agricultores de agave del municipio de Tequila volcaron todo su interés en iniciar la producción masiva de esta planta, a fin de venderla a las grandes casas tequileras.

4 En esta categoría se incluyen los 125 municipios de Jalisco, ocho de Nayarit, siete de Guanajuato, 30 de Michoacán (la segunda entidad más importante en la producción del tequila después de Jalisco) y 11 de Tamaulipas.

5 Datos obtenidos del Consejo Regulador del Tequila (http://www.crt.org.mx/EstadisticasCRTweb/)

6 Idem. 
Para lograrlo se incrementó considerablemente la superficie de cultivo dentro de todo el municipio, a tal grado que incluso se llegó a prescindir de otros productos como el maíz y el frijol. En consecuencia, se suscitó una progresiva disminución de tales terrenos, alcanzándose cifras alarmantes, ya que de 1990 a 1997 la siembra de estos productos pasó de 62000 a 50000 hectáreas y de ahí a 45000 hectáreas en el año 2000. Tal fue la necesidad de aumentar la producción de agave, que algunos agricultores pretendieron incluso acelerar el tiempo de maduración de la planta de entre siete y ocho años en tiempo normal, a tan sólo cuatro años en forma experimental.

Ante esta demanda, la mayor parte de los agricultores tuvieron que modificar sus antiguos sistemas de producción, ya que desde la época prehispánica y hasta nuestros días el cultivo del agave azul y los productos que de él se obtienen, como lazos, agujas, forraje, fertilizante, materiales de construcción, entre otros, han representado una forma de sustento inmejorable, independientemente de otras actividades (como el cultivo de maíz o la ganadería) a las que los agricultores también prestan atención. Sin embargo, dedicarse al cultivo del agave nunca implicó comprometer las tierras de las planicies (siempre mejores) ni implementar cualquier otro tipo de propagación utilizando técnicas distintas a las tradicionales; dicho de otra forma, esta labor para ellos siempre significó la continuidad de una añeja tradición heredada por sus padres, abuelos o bisabuelos como parte de una encomienda familiar.

Así, hasta antes de la mencionada crisis de sobrexplotación del agave, pocas tareas eran requeridas para la maduración de la planta; en la mayoría de los casos la unidad familiar se repartía las labores: durante las secas algunos cortaban los hijuelos, durante las lluvias otros "picaban" o "rayaban" la tierra con azadón para facilitar su oxigenación y otros más cultivaban maíz, frijol o calabaza. Sin embargo, ante la necesidad de incrementar en forma masiva la producción de agave azul, todas estas tareas - la mayoría de ellas ejecutadas a mano- no sólo se potencializaron, sino que además muchas de ellas fueron completamente sustituidas por el uso de nuevas y novedosas técnicas, así como el empleo de modernas maquinarias.

Ante esta situación sobrevinieron una serie de fenómenos — que hasta la fecha se mantienen - en torno a los agricultores de agave, por ejemplo, las labores culturales mencionadas se recalendarizaron para prácticamente todo el año, con ello emergió la fuerza de trabajo especializada — ejecutada ahora únicamente por aquellos agricultores considerados como especialistasconsistente en cuadrillas expertas en jima o cosecha, otras en desmonte y plantación, otras más en aplicación de agroquímicos. Asimismo, se presentan fenómenos relacionados con aspectos sociales y económicos: incremento de mano de obra calificada - generando con ello diferencias sociales dentro de 
los agricultores-, emigración e inmigración interna y externa, abaratamiento de la mano de obra no calificada, escasa participación social de los agricultores dentro de su misma comunidad, interacción entre expertos de distintas disciplinas, capacitación para el mejoramiento de determinadas actividades, organización en agrupaciones ejidales, desempleo, marginación, descomposición social y aculturación, entre muchos otros.

Como consecuencia de estos fenómenos surgirían entre los agricultores de agave azul una serie de necesidades de información — que aún se mantienen vigentes-, así como un comportamiento informativo - perfil informativo-, derivados de la urgencia de adaptarse a la sinergia del nuevo entorno que sus actividades económico-productivas les imponía. Dos acontecimientos terminarían por definir, en su totalidad, el actual perfil informativo de los agricultores de agave azul: 1) la denominación en el año 2003 del municipio de Tequila como Pueblo Mágico y 2) la declaratoria de la Organización de las Naciones Unidas para la Educación, la Ciencia y la Cultura (Unesco, por sus siglas en inglés) en el año 2006 del paisaje agavero como patrimonio de la humanidad.

\section{Del esplendor del boom tequilero a la ruina de los agaveros}

En el contexto descrito, los agricultores de Tequila, Jalisco (y en general de toda la región) se dedicaron a sembrar agave sin límite ni restricción alguna; a ello se sumó el hecho de que aquellos obreros que trabajaban en labores artesanales o industriales dentro de las grandes empresas tequileras dejaron estas labores para incorporarse a la siembra de dicha planta. La fiebre por el llamado "oro azul" llegó hasta sectores de profesionistas o empresarios de otros ramos como la industria de la construcción o la automotriz; hasta quienes otrora buscaban una mejor vida como inmigrantes en Estados Unidos optaron por dejar de "cruzar" hacia el vecino país del norte y buscar trabajo en la zona agavera, incluso aquellos que ya se encontraban allá regresaron ante las historias de bonanza que sus familiares les contaban sobre la siembra del mezcal.

Para esos años, el precio en la venta del agave por parte de sus productores alcanzó un monto de hasta $\$ 40.00$ por kilo, ${ }^{8}$ que convertido en toneladas daba como resultado una alta retribución económica nunca antes vista de su labor ancestral, situación que, como es de suponer, se vio reflejada en el poder adquisitivo, estilo de vida, idiosincrasia y expectativas a futuro de los agricultores.

8 Un agave maduro alcanza un peso de hasta 40 kilos. En una hectárea de cultivo llegan a producirse hasta 5000 plantas. 
No obstante, tal esplendor no sería tan prolongado: para mediados de la primera década del nuevo milenio, las grandes casas tequileras decidieron, en contubernio con los gobiernos local y federal, abaratar el precio del agave de forma arbitraria y con toda la intención de beneficiarse a sí mismos. Para el año 2006 el costo del agave tuvo una estrepitosa caída, llegando a un precio máximo de $\$ 16.00$ por kilo — hoy en día oscila entre $\$ 3.00$ y $\$ 0.50$ menos de $50 \%$ en comparación con los 10 años anteriores. Sumado a esto, las tasas bancarias se incrementaron enormemente para aquellos agricultores que habían solicitado programas de apoyo financiero, lo cual hizo que se sobreendeudaran considerablemente.

Todo esto, en conjunto con el desgaste de las tierras propiciado por la ya mencionada crisis de sobreproducción, provocó el colapso de los otrora beneficios económicos del boom tequilero de los que 10 años atrás habían disfrutado los agricultores de agave azul de Tequila.

Es entonces cuando muchos de ellos tuvieron que regresar a su antigua realidad. Ante lo poco redituable que comenzó a tornarse la producción de agave, algunos vendieron parte de sus tierras de cultivo, otros las alquilaron y, en el peor de los casos, otros más las vendieron en su totalidad para reincorporarse a sus antiguos puestos como empleados de las grandes casas tequileras, o bien, decepcionados del espejismo económico del "oro azul", decidieron abandonar por completo el cultivo de tan emblemática planta, surgiendo con ello una nueva crisis: el desempleo.

\section{Tequila Pueblo Mágico}

A partir del año 2003, la Secretaría de Turismo (Sectur) del gobierno federal incluyó al municipio de Tequila, Jalisco, en el programa denominado Pueblos Mágicos, distinción que se otorga a todas aquellas localidades que, entre otras características, cuentan con un amplio potencial de desarrollo como destinos turísticos.

Los primeros cuatro años después de la denominación el pueblo recibió recursos económicos con un valor aproximado de 1.5 millones de dólares de parte del comité correspondiente (Gómez Arriola, 2009), los cuales fueron destinados al remozamiento de la imagen urbana del centro de Tequila y a la creación de infraestructura destinada a la prestación de servicios.

El ingreso de Tequila entre las localidades distinguidas por la Sectur para ser consideradas Pueblo Mágico se debió a las gestiones de un pequeño grupo de empresarios, propietarios de las más importantes empresas de la industria tequilera mexicana (Cuervo, Sauza y Herradura), interesados en aprovechar dicha denominación para promocionar el tequila, aunque de una forma 
más enfocada en la valoración histórica y cultural de una industria que, de una u otra manera, ha sido representativa de la idiosincrasia y la cultura nacionales durante muchos años.

Entre algunas de las obras de remozamiento y reconstrucción más importantes dentro del pueblo destacaron la restauración de la imagen urbana, obras de infraestructura arquitectónica, alumbrado, drenaje, pavimentación de calles, instalación de cableado eléctrico y telefonía oculta, jardinería, arbolado, iluminación artística de monumentos, entre muchas otras. Asimismo, el gobierno municipal en turno invirtió de forma alterna en la construcción y remozamiento de escuelas, la ampliación del Instituto Tecnológico, la promoción de las ruinas arqueológicas de los Guachimontones y de la catedral de Santiago Apóstol.

La denominación de Pueblo Mágico y su consiguiente inversión económica rápidamente colocaron al municipio de Tequila como el tercer punto más importante de interés turístico dentro del estado de Jalisco, sólo detrás de su capital, Guadalajara, y de su principal playa, Puerto Vallarta. Todo lo anterior sirvió como punta de lanza para lograr la incorporación de su principal atractivo dentro de la lista del patrimonio de la humanidad de la Unesco: el paisaje agavero.

\section{La declaratoria de la Unesco del paisaje agavero como patrimonio de la humanidad}

Justo en medio de la crisis económica de los agricultores de agave derivada de la sobreexplotación de dicha planta, en el año 2006, luego de la denominación de Tequila como Pueblo Mágico, los ojos del mundo volcaron su atención hacia la riqueza paisajística, histórica, cultural y artística de este municipio.

La declaratoria de la Unesco comprende una extensión de 38658 hectáreas de agave plantado entre el Volcán de Tequila y el profundo valle del Río Grande de Santiago; los vestigios arqueológicos de las ruinas de los Guachimontones; las antiguas fábricas de tequila — también conocidas como tabernas-; las actuales destilerías; diversas construcciones coloniales - la mayoría de ellas reconstruidas luego de la denominación de Pueblo Mágico-y la catedral de Santiago Apóstol (Gómez Arriola, 2006).

A partir de entonces, y dado el atractivo que esta situación imprimió al municipio de Tequila — principal productor de la bebida que lleva el mismo nombre-, los ojos de la inversión turística local y estatal se posaron en él y enfocaron su interés en el desarrollo de un punto mediático al occidente del país, ofreciendo así diferentes expresiones de la belleza y riqueza del lugar a los turistas nacionales y extranjeros, pues además de la ya mencionada 
reconstrucción del pueblo, se erigieron más fábricas de tequila y mediante fuertes inversiones se implementaron recorridos en tren y autobús y paseos en globo, entre otras ofertas turísticas.

Todo esto atrajo muchos más visitantes nacionales y extranjeros, se filmaron películas, comerciales y telenovelas — llegando con ello artistas, actores, escritores, poetas, pintores, etc.- - se construyeron hoteles, restaurantes, museos, y centros de diversión; consecuentemente, los habitantes del lugar cambiaron sus hábitos, sus costumbres, su forma de hablar y de vestir, entre muchas otras cosas más, de manera que se suscitó un proceso de aculturación.

Ante los cambios, y dadas las necesidades económicas y laborales de los agricultores de agave, éstos se vieron orillados a insertarse dentro de la transformación de su entorno o, dicho de otra forma, los agaveros terminaron por abandonar su oficio ancestral de cultivar el agave, así como su estilo de vida, idiosincrasia y proyección futura, para incorporarse a la sinergia de los cambios ocurridos dentro del pueblo y su nueva organización social.

A causa de dicha incorporación, muchos de los agricultores se emplearon como taxistas, vendedores de artesanías y recuerdos, policías, empleados de hotel, meseros, improvisados guías de turistas, entre muchos otros oficios. Algunos que contaban con mayor preparación se incorporaron como guías de turistas autorizados, empleados bancarios, oficinistas, promotores culturales, pequeños empresarios, recepcionistas y demás actividades formales.

Al igual que en el caso descrito en el apartado correspondiente a las necesidades de información surgidas del nuevo entorno de los agaveros, el proceso de incorporación de los agricultores a sus nuevos oficios y a su nuevo ambiente turístico-cultural provocó el surgimiento de otras necesidades de información, que sumadas a las anteriores, delinearon en su totalidad el actual perfil informativo de estos grupos de población.

A continuación se presenta un análisis del estado actual que guardan los agricultores de agave azul del municipio de Tequila, Jalisco, así como de su perfil informativo, derivado de los acontecimientos relatados.

\section{Estado ACTUAL DE LOS AGRICULTORES DE AGAVE AZUL de Tequila, Jalisco}

Hasta hace no muchos años se creía que el agave azul era una planta agreste que surgía de manera espontánea, natural, casi mágica; prácticamente sin necesidad de aplicar alguna técnica por parte de un ser humano. Contrario a esta creencia hoy en día, y como nunca antes en los últimos 15 ó 20 años, se requiere de gran cantidad de mano de obra para el despliegue de las activi- 
dades laborales relacionadas con el cultivo del agave azul, tanto en el campo como en la misma industria tequilera. No obstante, cada vez son menos conocidas las historias de vida relacionadas con esa mano de obra ejecutante de aquellos agricultores que en pleno siglo XXI siguen cultivando la planta tal y como lo hacían los primeros pobladores del municipio.

Si bien es cierto que para ellos existe mucho trabajo, sus condiciones de vida, lejos de mejorar — como sucedió en los años noventa—, han empeorado. $\mathrm{Al}$ parecer, para las grandes empresas tequileras que los contratan es importante contar con su fuerza de trabajo, pero no mejorar sus condiciones socioeconómicas. Algunas empresas, por ejemplo, desde el año 2000 únicamente ofrecen a los obreros y a las cuadrillas de agaveros contratos por 100 días, con salarios que en nada corresponden a su labor ancestral, evitando así la obligación de otorgar prestaciones como seguro social, vacaciones y aguinaldo.

En semejantes circunstancias, muchos de estos agricultores han optado por otras formas de retribución económica, particularmente las relacionadas con el comercio y/o venta de artesanías y recuerdos típicos del lugar, o bien por el desarrollo de algún oficio alejado completamente del cultivo del agave.

No obstante, también existe otro tipo de agaveros que de una u otra forma lograron superar las condiciones en las que se encuentran algunos de sus colegas. Dichos agricultores supieron introducir su producto en las grandes empresas tequileras, trascendiendo así su simple papel como mano de obra y, en su lugar, se convirtieron en sus principales distribuidores de materia prima, con lo cual alcanzaron mejores condiciones de vida y una mayor proyección a futuro.

Si bien es cierto que la introducción de la tecnología y la ciencia en el ramo del agave ha traído una mejor y mayor expansión de los terrenos de cultivo en su hábitat y un mejor rendimiento y aprovechamiento del agave azul, para estos agricultores dicha irrupción no ha significado el desplazamiento de la mano de obra especializada que ellos mismos ofrecen.

De cualquier modo, la mayor parte de ellos ha tenido que ajustarse a las exigencias de lo que hoy en día, a diferencia de décadas anteriores, es toda una industria, con lo que ello representa. En muchos casos, por ejemplo, estos agaveros han tenido que asistir a diversos cursos y/o talleres con el fin de actualizarse en el conocimiento y aplicación de nuevas técnicas de cultivo o para el uso de nuevas formas de control de plagas y enfermedades.

Finalmente, también existen algunos otros agricultores de agave que, a causa de su mejor posición económica —en muchos de los casos heredada de sus padres o abuelos - han logrado insertarse dentro de la cadena productiva agave-tequila, aunque de forma aún inferior en comparación con las grandes casas tequileras. 
Estos acaudalados agaveros - a diferencia de los que únicamente pueden ofrecer su mano de obra- han optado por dejar un poco de lado la producción de agave a su cargo y han empleado a algunos de sus colegas especialistas para conformar aquellas cuadrillas de agricultores con contratos de 100 días que se mencionaron anteriormente.

Las circunstancias de estos agaveros, combinadas con los cambios sociales, culturales y económicos sufridos en el municipio de Tequila, provocaron que hoy en día se hable de una estratificación o jerarquización de los agricultores de agave azul, con base en los siguientes elementos:
a) Tenencia de la tierra;
b) Superficie de la tierra que se cultiva;
c) Relación compraventa con las grandes casas tequileras;
d) Condiciones socioeconómicas y culturales de los agricultores, y
e) Proyección de vida.

En ese sentido, se puede determinar que hoy en día existen seis tipos diferentes de agricultores de agave azul:

1. Agaveros empresarios;

2. Agaveros independientes;

3. Agaveros que alquilan sus parcelas;

4. Agaveros que trabajan para las casas tequileras;

5. Jornaleros, y

6. Mujeres agricultoras de agave azul.

Para efectos de esta investigación, únicamente se consideraron los agricultores independientes y los agricultores que alquilan sus parcelas. Este criterio responde al hecho de que estos dos tipos de agaveros son los que, de alguna manera, han sabido combinar de forma más afortunada las prácticas antiguas de la producción de agave con los implementos que ofrece la modernidad. Asimismo, también es posible afirmar que son estos agricultores los que mejor representan la base de la cadena productiva de la planta de agave.

Se considera que el perfil informativo de estos agricultores es más representativo del estado actual que guardan los miembros de esta población, de acuerdo con lo señalado en el inicio de este apartado. A continuación se hace una descripción general de las características particulares de estos agricultores, tomando en consideración los elementos anteriormente enlistados: 
Agricultores independientes

a) Son propietarios de sus tierras.

b) Cuentan con una superficie de cultivo de entre 15 y 20 hectáreas.

c) Venden su producto de forma directa a las grandes casas tequileras.

d) Algunos cuentan con estudios profesionales; sus ingresos anuales son altos; viajan constantemente; su poder adquisitivo es elevado; habitualmente están asociados con algún organismo; con frecuencia acuden a eventos locales relacionados con el agave azul, etc.

e) Desean comprar más extensiones de tierra para producir agave azul y vender más producto a las casas tequileras.

Agricultores que alquilan sus parcelas

a) La mayoría son dueños de sus tierras, aunque algunos son medieros.

b) Cuentan con una superficie de entre 5 y 10 hectáreas.

c) Alquilan sus tierras a las grandes casas tequileras, e incluso en algunos casos a los mismos agricultores independientes.

d) Sus ingresos anuales oscilan en una escala media baja; algunos crían ganado, otros trabajan en el turismo, algunos tienen tiendas de tequila y recuerdos, otros son taxistas; cuentan con un nivel medio de estudios; su poder adquisitivo es intermedio; compran autos, ropa, tequila; viajan a Guadalajara, Colima, Tepic, al norte del país, etc.

e) Desean cultivar ellos mismos sus tierras y vender directamente su producto a las grandes casas tequileras.

\section{Metodología}

\section{Tipo de investigación}

Se trata de una investigación exploratorio-descriptiva. En su fase exploratoria se llevó a cabo la primera visita al municipio de Tequila, Jalisco, y se establecieron los primeros contactos con los informantes clave. Con base en las observaciones y los contactos realizados, en la fase descriptiva se determinó lo siguiente:

- El contexto económico-laboral y sociocultural del municipio de Tequila incide directamente en el desarrollo de una tipología o jerarquización no oficial de los actuales agricultores de agave azul.

- De acuerdo con la tipología establecida se determinó que el perfil informativo de los agricultores que participaron en el estudio está de- 
finido, en gran medida, por sus condiciones laborales, económicas y socioculturales.

\section{Método de investigación}

Investigación documental: se llevó a cabo la revisión bibliográfica de los documentos pertinentes relacionados con el tema.

Investigación de campo: se realizaron dos visitas más al municipio de Tequila, Jalisco, de la siguiente forma:

- Segunda visita: se realizaron entrevistas preliminares dirigidas a los informantes clave, apoyándose en el uso de una grabadora.

- Tercera visita: se aplicó un instrumento estructurado (Anexo), específicamente diseñado para la investigación a los integrantes de la muestra que correspondieron con la población objetivo de este estudio.

\section{Población}

El procedimiento para identificar la población y muestra correspondientes consistió en extraer del Sistema de Información Estadística y Geográfica de Jalisco (SIEG) los datos relacionados con el número de trabajadores permanentes y eventuales que laboran en el sector agrícola dentro del municipio de Tequila y que se encuentran registrados en el Instituto Mexicano del Seguro Social. El número de agricultores que cuentan con dicho registro es de 285 personas, se estima que aproximadamente $80 \%$ de ellos está dedicado al cultivo del agave azul, es decir, alrededor de 228 personas.

\section{Muestra}

De la población mencionada (228 agricultores de agave) fueron localizados un total de 180 agricultores, lo cual representa casi $80 \%$. Con base en la tipología mencionada, se determinó el número de agricultores que corresponde a cada categoría (Tabla 1$)$.

Tabla 1

\begin{tabular}{|l|c|}
\hline \multicolumn{1}{|c|}{ Tipo de agricultor } & Cantidad \\
\hline Agricultores empresarios & 30 \\
\hline Agricultores independientes & 25 \\
\hline Agricultores que alquilan sus parcelas & 25 \\
\hline Agricultores que trabajan para las casas tequileras & 35 \\
\hline
\end{tabular}




\begin{tabular}{|l|l|}
\hline Jornaleros & 35 \\
\hline Mujeres agricultoras de agave azul & 30 \\
\hline
\end{tabular}

Para efectos específicos de esta investigación, únicamente se consideraron en la muestra los 25 agricultores independientes y los 25 agricultores que alquilan sus parcelas.

\section{Resultados}

\section{Datos generales}

Como se dijo anteriormente, el primer paso de la metodología consistió en ubicar a cinco informantes clave de cada tipo de agricultor, en este caso serían cinco agricultores independientes y cinco agricultores que alquilan sus parcelas. Posteriormente cada uno de ellos facilitó el contacto con otros cuatro agricultores más, dando un total de 50 agricultores entrevistados (Tabla 2).

Tabla 2

\begin{tabular}{|c|c|c|}
\hline $\begin{array}{c}\text { Agricultores } \\
\text { independientes }\end{array}$ & $\begin{array}{c}\text { Agricultores que alquilan } \\
\text { sus parcelas }\end{array}$ & $\begin{array}{c}\text { Total de agricultores } \\
\text { entrevistados }\end{array}$ \\
\hline 25 & 25 & 50 \\
\hline
\end{tabular}

De los 50 agricultores entrevistados todos fueron hombres y sus rangos de edad fluctuaron desde los 25 hasta más de 60 años, distribuidos de la siguiente manera (Tabla 3):

Tabla 3

\begin{tabular}{|c|c|c|}
\hline Rangos de edad & Número de agricultores & Porcentaje \\
\hline 25 a 30 años & 5 & $10.00 \%$ \\
\hline 31 a 40 años & 12 & $24.00 \%$ \\
\hline 41 a 50 años & 21 & $42.00 \%$ \\
\hline 51 a 60 años & 8 & $16.00 \%$ \\
\hline 61 años o más & 4 & $8.00 \%$ \\
\hline
\end{tabular}

Del total de entrevistados, todos cultivan el agave azul dentro del territorio perteneciente al municipio de Tequila, Jalisco, aunque algunos no son oriundos de dicho lugar. El número total de agricultores entrevistados que nacieron en Tequila es de 40, mientras que cinco son originarios de Amatitán, tres de Guadalajara y tan sólo uno de Arandas (Tabla 4). 
Tabla 4

\begin{tabular}{|c|c|c|c|c|}
\hline $\begin{array}{c}\text { Agricultores nacidos } \\
\text { en Tequila }\end{array}$ & $\begin{array}{c}\text { Agricultores nacidos } \\
\text { en Amatitán }\end{array}$ & $\begin{array}{c}\text { Agricultores nacidos } \\
\text { en Guadalajara }\end{array}$ & $\begin{array}{c}\text { Agricultores nacidos } \\
\text { en Arandas }\end{array}$ & Total \\
\hline 40 & 6 & 3 & 1 & 50 \\
\hline
\end{tabular}

En cuanto al nivel de estudios de los entrevistados, 12 manifestaron haber concluido la primaria, 20 la secundaria, 12 el bachillerato y tan sólo seis cuentan con alguna licenciatura — de estos últimos sólo en tres casos sus estudios profesionales están relacionados con la agronomía- (Tabla 5).

Tabla 5

\begin{tabular}{|l|c|}
\hline \multicolumn{1}{|c|}{ Nivel de estudios } & Número de agricultores \\
\hline Primaria & 12 \\
\hline Secundaria & 20 \\
\hline Bachillerato & 12 \\
\hline Licenciatura & 6 \\
\hline
\end{tabular}

Por otra parte, el número de agricultores que alternan su labor de cultivar el agave con alguna otra actividad remunerada (oficio y/o profesión) es la siguiente: 32 realizan algún otro tipo de actividad económicamente remunerada, de los cuales 25 pertenecen al grupo de agricultores que alquilan sus parcelas y sólo siete a los agricultores independientes.

En cuanto a los agricultores dedicados únicamente al cultivo del agave, sumaron 18, siendo en su totalidad agricultores independientes (Tabla 6).

Tabla 6

\begin{tabular}{|l|c|c|c|}
\hline Actividad & $\begin{array}{c}\text { Agricultores } \\
\text { Independientes }\end{array}$ & $\begin{array}{c}\text { Agricultores que alquilan } \\
\text { sus parcelas }\end{array}$ & Total \\
\hline $\begin{array}{l}\text { Alternan su labor con algún } \\
\text { otro oficio y/o profesión }\end{array}$ & 7 & 25 & 32 \\
\hline $\begin{array}{l}\text { Dedicados únicamente al } \\
\text { cultivo del agave }\end{array}$ & 18 & 0 & 18 \\
\hline
\end{tabular}

\section{Análisis de resultados}

Después de conocer el estado actual de los agricultores de agave azul de Tequila, Jalisco, así como de determinar la muestra de la población a ser investigada, en este apartado se presenta el análisis de los resultados obtenidos de la aplicación del instrumento diseñado para recolectar la información (Ane$x o)$. 
Tomando en cuenta los dos tipos de agricultores que corresponden a nuestra muestra, en cada apartado los resultados obtenidos se presentan en dos partes. En la primera se hace mención de las necesidades de información y el comportamiento informativo en relación con su actividad como agricultores de agave azul, mientras que en la segunda se hace referencia a estas mismas variables, pero en relación con su vida cotidiana, contexto social, idiosincrasia y actividades económicas complementarias. Los resultados serán presentados mediante tablas y gráficas para facilitar su comprensión.

\section{Perfil informativo de los agricultores independientes}

\section{Necesidades de información como agricultores de agave azul}

Tal como lo indican los resultados obtenidos, los temas que representan las necesidades de información más frecuentes en los agricultores independientes son uso y aplicación de fertilizantes, control de plagas y enfermedades y regulaciones del Consejo Regulador del Tequila (CRT) (con un total de 25 registros cada uno); maquinaria agrícola (23 registros); certificaciones orgánicas y legislación agrícola (21 registros cada uno); créditos agrícolas (20 registros); agricultura y desarrollo sustentable (16 registros); agricultura intensiva (14 registros); exportación y agroindustria (10 registros); insumos agrícolas (8 registros) y otros varios (6 registros) (Tabla 7 y Gráfica 1$)$.

Tabla 7

\begin{tabular}{|l|c|}
\hline \multicolumn{1}{|c|}{ Necesidades de información } & Frecuencia \\
\hline Uso y aplicación de fertilizantes & 25 \\
\hline Control de plagas y enfermedades & 25 \\
\hline Regulaciones del CRT & 25 \\
\hline Maquinaría agrícola & 23 \\
\hline Certificaciones orgánicas & 21 \\
\hline Legislación agrícola & 21 \\
\hline Créditos agrícolas & 20 \\
\hline Agricultura y desarrollo sustentable & 16 \\
\hline Agricultura intensiva & 14 \\
\hline Exportación y agroindustria & 10 \\
\hline Insumos agrícolas & 8 \\
\hline Otros & 6 \\
\hline
\end{tabular}




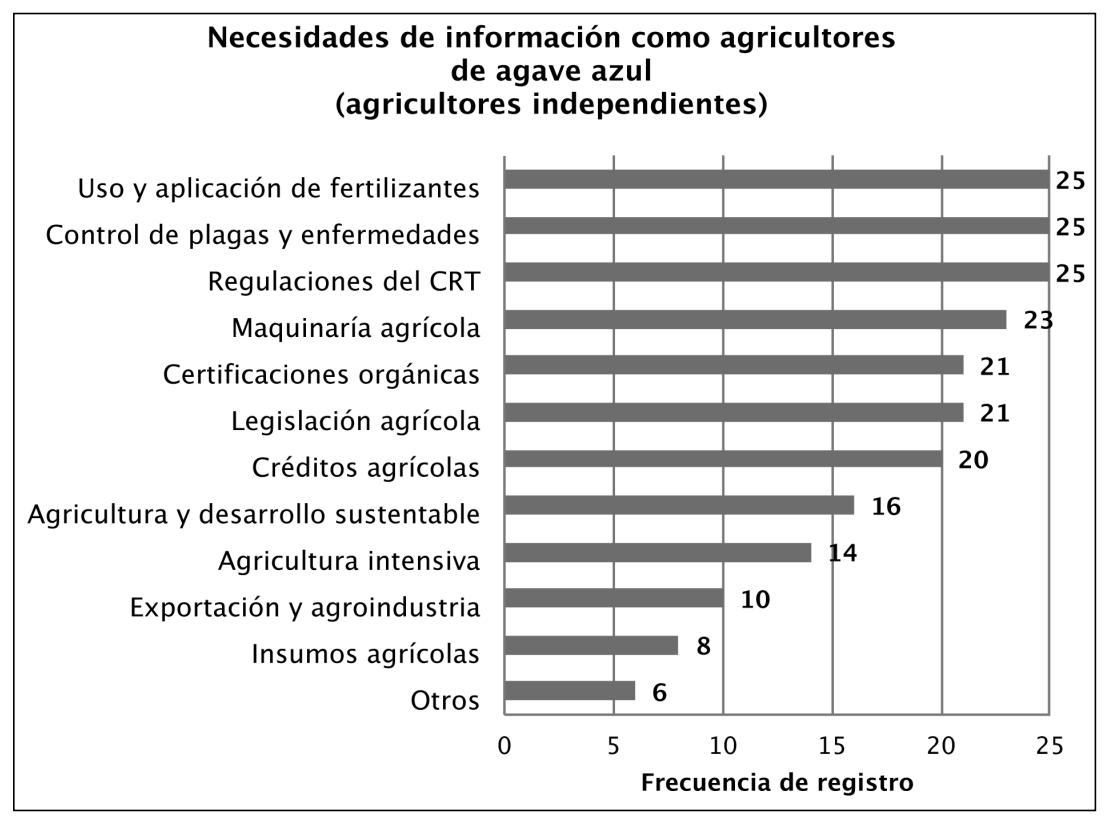

Gráfica 1

Fuentes y recursos que consultan como agricultores de agave azul

Por otra parte, las fuentes y recursos más consultados por los agricultores independientes para satisfacer sus necesidades de información son reuniones del CRT (25 registros); sus mismos colegas agricultores (24 registros); manuales del CRT (22 registros); Internet (20 registros); distribuidores de agroquímicos (16 registros); agencias de compraventa de maquinaria (15 registros); instituciones bancarias (12 registros); eventos relacionados con el tequila (10 registros); revista Tecnoagave ( 8 registros) y otros varios (6 registros) (Tabla 8 y Gráfica 2).

Tabla 8

\begin{tabular}{|l|c|}
\hline \multicolumn{1}{|c|}{ Fuentes y recursos } & Frecuencia \\
\hline Reuniones del CRT & 25 \\
\hline Colegas agricultores & 24 \\
\hline Manuales del CRT & 22 \\
\hline Internet & 20 \\
\hline Distribuidores de agroquímicos & 16 \\
\hline $\begin{array}{l}\text { Agencias de compraventa de } \\
\text { maquinaria }\end{array}$ & 15 \\
\hline Instituciones bancarias & 12 \\
\hline
\end{tabular}




\begin{tabular}{|l|c|}
\hline Eventos sobre el tequila & 10 \\
\hline Revista Tecnoagave & 8 \\
\hline Otros & 6 \\
\hline
\end{tabular}

\section{Fuentes y recursos informativos que consultan como agricultores de agave azul (agricultores independientes)}

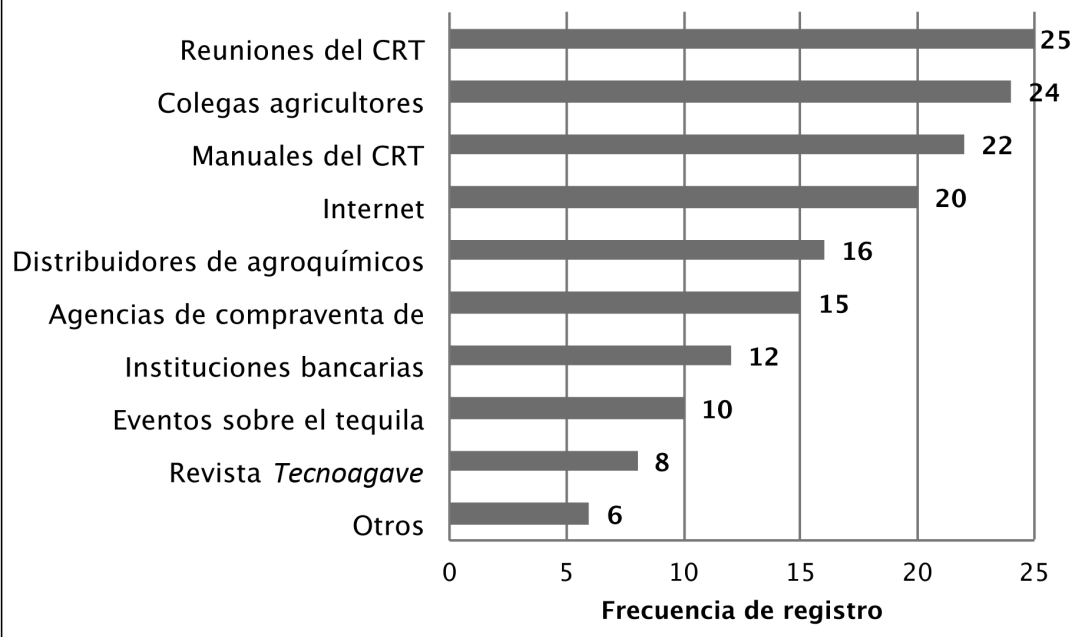

Gráfica 2

\section{Necesidades de información en el seno de la vida cotidiana}

En cuanto a las necesidades de información que los agricultores independientes manifiestan tener en el transcurso de su vida cotidiana, éstas tienen que ver principalmente con los siguientes temas: todo lo relacionado con la compraventa del agave (25 registros); conceptos básicos relacionados con agronomía (24 registros); datos relacionados con la impartición de cursos de capacitación en agronomía ( 23 registros); conocimientos relacionados con cultivo de hortalizas y animales de crianza (cada uno con 22 registros); el cultivo de otras plantas comestibles (21 registros); conocimientos básicos de administración y contabilidad (20 registros); precios de camiones de carga y sus refacciones (18 registros); precios de automóviles nuevos y seminuevos, así como de sus refacciones (14 registros); eventos de esparcimiento y diversión (12 registros); lugares de descanso y vacaciones (10 registros); costo de hospedaje en hoteles ( 8 registros) y boletos de avión y autobús (4 registros) (Tabla 9 y Gráfica 3). 
Tabla 9

\begin{tabular}{|l|c|}
\hline \multicolumn{1}{|c|}{ Necesidades de información } & Frecuencia \\
\hline Todo lo relacionados con la compraventa de agave & 25 \\
\hline Conceptos básicos de agronomía & 24 \\
\hline Datos de impartición de cursos & 23 \\
\hline Cultivo de hortalizas & 22 \\
\hline Animales de crianza & 22 \\
\hline Cultivo de plantas comestibles & 21 \\
\hline Conocimientos de administración y contabilidad & 20 \\
\hline Precios de camiones de carga y sus refacciones & 18 \\
\hline Precios de automóviles y sus refacciones & 14 \\
\hline Eventos de esparcimiento y diversión & 12 \\
\hline Lugares de descanso y vacaciones & 10 \\
\hline Costo de hospedaje en hoteles & 8 \\
\hline Boletos de avión y autobús & 4 \\
\hline
\end{tabular}

\section{Necesidades de información en la vida cotidiana (agricultores independientes)}

Lo relacionado con la compraventa de

Conceptos básicos de agronomía

Datos de impartición de cursos

Cultivo de hortalizas

Animales de crianza

Cultivo de plantas comestibles Conocimientos de administración y

Precios de camiones de carga y sus

Precios de automóviles y sus

Eventos de esparcimiento y diversión

Lugares de descanso y vacaciones

Costo de hospedaje en hoteles

Boletos de avión y autobús

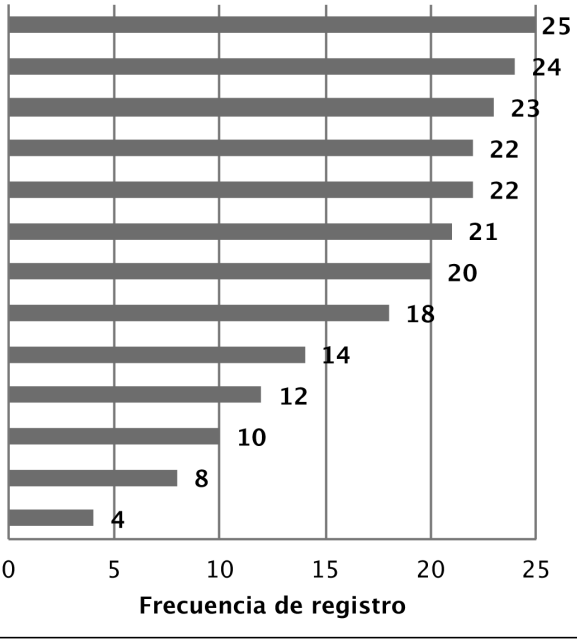

Gráfica 3

Fuentes y recursos que consultan en el seno de la vida cotidiana

Para satisfacer las necesidades de información mencionadas, los agricultores independientes acuden a las siguientes fuentes y/o recursos: al igual que en el caso anterior, el CRT resultó ser la fuente y/o recurso más consultado por los agricultores independientes ( 25 registros), seguido de sus mismos colegas 
agricultores (24 registros); ingenieros agrónomos (20 registros); jornaleros experimentados (19 registros); Internet (18 registros); ganaderos habitantes del municipio (16 registros); estación de radio La Tapatía (15 registros); capacitadores técnicos (13 registros); agencias de maquinaria agrícola (10 registros); agencias de autos ( 9 registros); familiares y/o amigos (6 registros) y diccionarios y/o libros especializados (2 registros) (Tabla 10 y Gráfica 4).

Tabla 10

\begin{tabular}{|l|c|}
\hline \multicolumn{1}{|c|}{ Fuentes y recursos } & Frecuencia \\
\hline Reuniones del CRT & 25 \\
\hline Colegas agricultores & 24 \\
\hline Ingenieros agrónomos & 20 \\
\hline Jornaleros experimentados & 19 \\
\hline Internet & 18 \\
\hline Ganaderos habitantes del municipio & 16 \\
\hline Estación de radio La Tapatía & 15 \\
\hline Capacitadores técnicos & 13 \\
\hline Agencias de maquinaria agrícola & 10 \\
\hline Agencias de automóviles & 9 \\
\hline Familiares y/o amigos & 6 \\
\hline Diccionarios y/o libros especializados & 2 \\
\hline
\end{tabular}

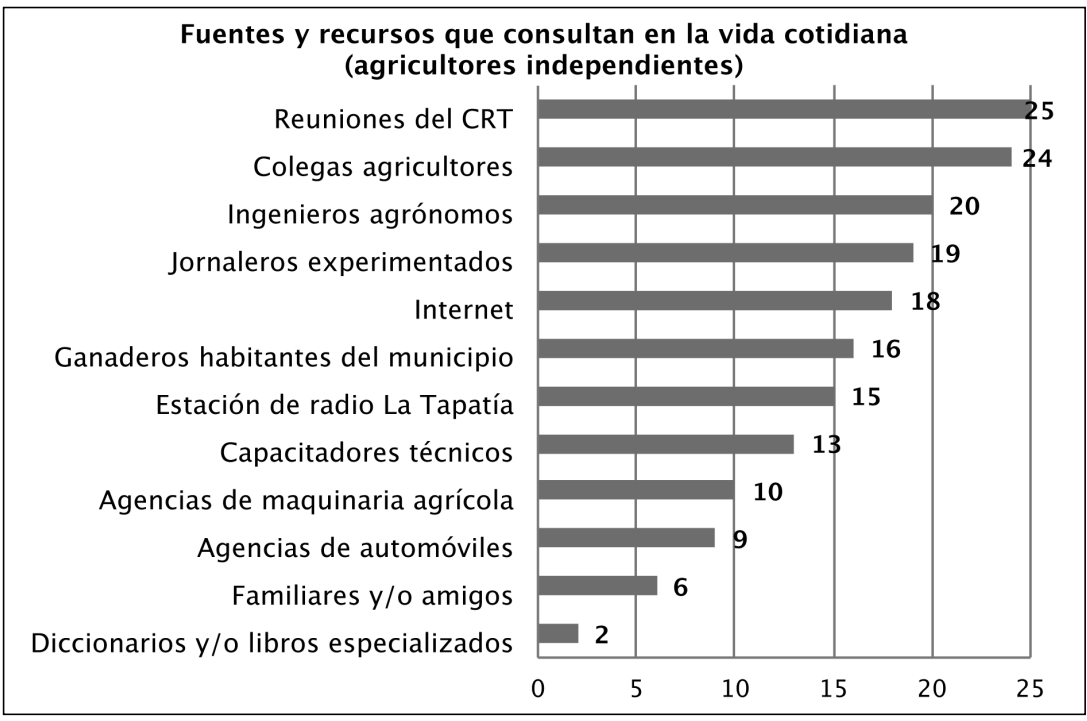

Gráfica 4 


\section{Perfil informativo de agricultores que alquilan sus parcelas}

\section{Necesidades de información como agricultores de agave azul}

En relación con los resultados de las entrevistas realizadas al grupo de agricultores que alquilan sus parcelas, las necesidades de información detectadas fueron las siguientes: uso y aplicación de nuevas técnicas de cultivo (20 registros); nuevos procesos de producción del agave (18 registros); uso y aplicación de agroquímicos (16 registros); financiamientos gubernamentales y créditos agrícolas (13 registros cada uno); créditos bancarios (12 registros); control de plagas y enfermedades y regulaciones del CRT (10 registros cada uno); legislación agraria (6 registros); precios de compraventa del agave (4 registros); costo de maquinaria agrícola (3 registros); costo de herramientas de cultivo y otros varios (2 registros cada uno) (Tabla 11 y Gráfica 5).

Tabla 11

\begin{tabular}{|l|c|}
\hline \multicolumn{1}{|c|}{ Necesidades de información } & Frecuencia \\
\hline Nuevas técnicas de cultivo & 20 \\
\hline Nuevos procesos de producción & 18 \\
\hline Uso y aplicación de agroquímicos & 16 \\
\hline Financiamientos gubernamentales & 13 \\
\hline Créditos agrícolas & 13 \\
\hline Créditos bancarios & 12 \\
\hline Control de plagas y enfermedades & 10 \\
\hline Regulaciones del CRT & 10 \\
\hline Legislación agraria & 6 \\
\hline Compraventa de agave & 4 \\
\hline Costo de maquinaria agrícola & 3 \\
\hline Costo de herramientas de cultivo & 2 \\
\hline Otros & 2 \\
\hline
\end{tabular}




\section{Necesidades de información como agricultores \\ de agave azul \\ (agricultores que alquilan sus parcelas)}

Nuevas técnicas de cultivo

Nuevos procesos de producción

Uso y aplicación de agroquímicos

Financiamientos gubernamentales

Créditos agrícolas

Créditos bancarios

Control de plagas y enfermedades

Regulaciones del CRT

Legislación agraria

Compraventa de agave

Costo de maquinaria agrícola

Costo de herramientas de cultivo

Otros

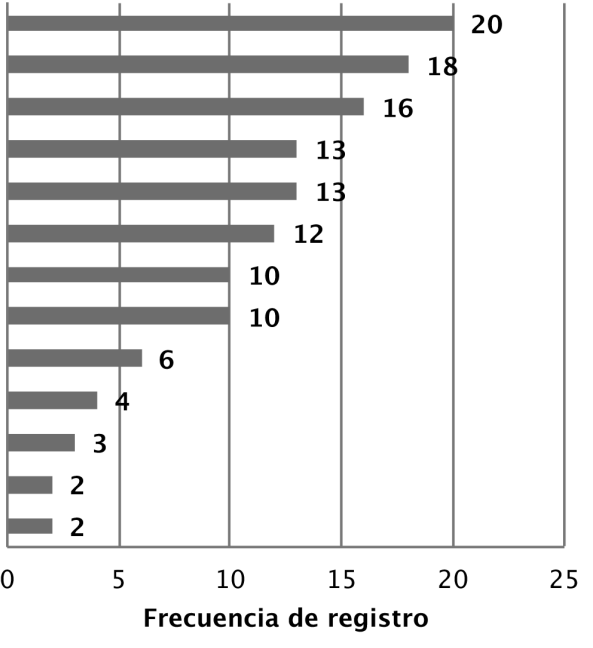

Gráfica 5

Fuentes y recursos que consultan como agricultores de agave azul

Las fuentes y/o recursos a los que estos agricultores acuden con mayor frecuencia para satisfacer sus necesidades de información son los siguientes: cursos y talleres que imparte el gobierno (20 registros); colegas agricultores (20 registros); asambleas de ejidatarios y organizaciones de agaveros (18 registros cada uno); el CRT (16 registros); jóvenes agaveros que cuentan con estudios e ingenieros agrónomos (14 registros cada uno); instituciones bancarias (12 registros); bancos agrícolas (10 registros); distribuidores de fertilizantes ( 8 registros) y empresas tequileras (4 registros) (Tabla 12 y Gráfica 6).

Tabla 12

\begin{tabular}{|l|c|}
\hline \multicolumn{1}{|c|}{ Fuentes y recursos } & Frecuencia \\
\hline Cursos y talleres & 20 \\
\hline Colegas agricultores & 20 \\
\hline Asambleas ejidatarias & 18 \\
\hline Organizaciones de agaveros & 18 \\
\hline El CRT & 16 \\
\hline Jóvenes agaveros & 14 \\
\hline Ingenieros agrónomos & 14 \\
\hline
\end{tabular}




\begin{tabular}{|l|c|}
\hline Instituciones bancarias & 12 \\
\hline Bancos agrícolas & 10 \\
\hline Distribuidores de fertilizantes & 8 \\
\hline Empresas tequileras & 4 \\
\hline
\end{tabular}

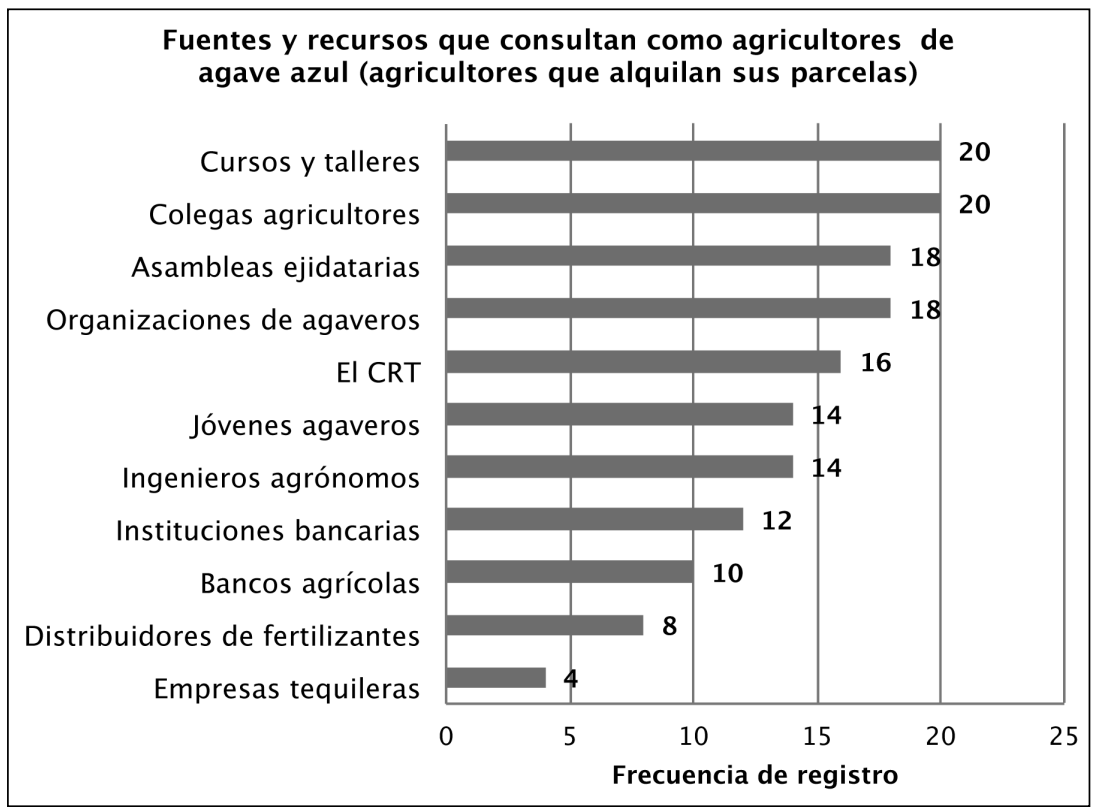

Gráfica 6

Necesidades de información en el seno de la vida cotidiana $y$ otros oficios

Tal como se dijo en el apartado correspondiente al estado actual que guardan los agricultores de agave azul de Tequila, Jalisco, hoy en día aquellos agricultores que alquilan sus parcelas ya no viven exclusivamente de la producción de agave azul; en ese sentido sus vidas, idiosincrasia y aspiraciones futuras han tenido que adaptarse a esta nueva situación. Sus necesidades de información más frecuentes son las siguientes: cifras de las casas tequileras, historia del municipio e historia y términos en inglés (25 registros cada uno); historia del tequila (24 registros); datos históricos sobre sitios importantes del pueblo (23 registros); precios y marcas de tequila (22 registros); conocimiento sobre elaboración de artesanías (20 registros); sitios de interés de la región (18 registros); eventos regionales (16 registros); festividades (15 registros); noticias de la región (12 registros); fechas cívicas importantes y sitios 
de esparcimiento y diversión (10 registros para cada uno); escuelas de turismo e inglés (9 registros) y otros varios (8 registros) (Tabla 13 y Gráfica 7).

Tabla 13

\begin{tabular}{|l|c|}
\hline \multicolumn{1}{|c|}{ Necesidades de información } & Frecuencia \\
\hline Casas tequileras & 25 \\
\hline Historia del municipio & 25 \\
\hline Términos en inglés & 25 \\
\hline Historia del tequila & 24 \\
\hline Datos sobre sitios importantes del pueblo & 23 \\
\hline Precios y marcas de tequila & 22 \\
\hline Elaboración de artesanías & 20 \\
\hline Sitios de interés de la región & 18 \\
\hline Eventos regionales & 16 \\
\hline Festividades & 15 \\
\hline Noticias de la región & 12 \\
\hline Fechas cívicas & 10 \\
\hline Esparcimiento y diversión & 10 \\
\hline Escuelas de turismo e inglés & 9 \\
\hline Otros & 8 \\
\hline
\end{tabular}

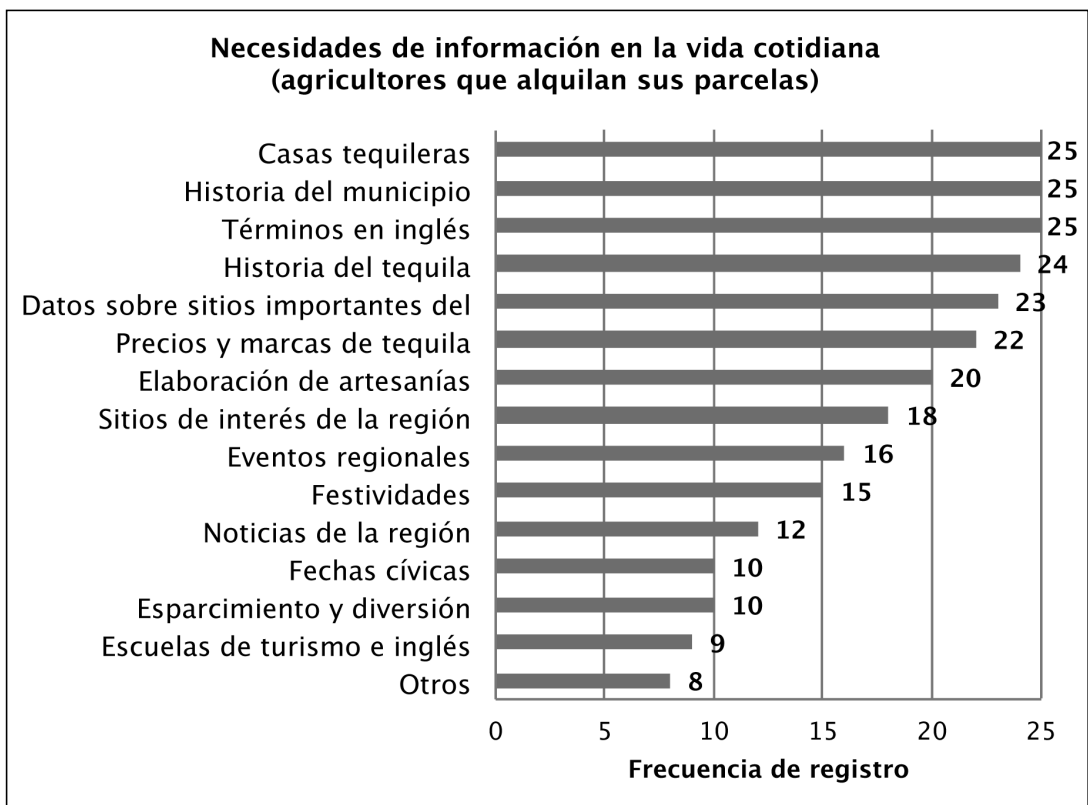


Fuentes y recursos que consultan en el seno de la vida cotidiana y otros oficios

Las fuentes y recursos a los que acuden este tipo de agricultores para satisfacer sus necesidades de información son las siguientes: Internet y diccionarios inglés-español resultan ser las fuentes de información más consultadas (25 registros cada uno); estudiantes y profesores habitantes del municipio (20 registros); arqueólogos, antropólogos e historiadores de la región (18 registros); fábricas de tequila (15 registros); sus mismos colegas agricultores (14 registros); fabricantes de artesanías y fabricantes de tequila (12 registros cada uno); eventos de la región relacionados con el agave y el tequila (10 registros); bibliotecas públicas ( 8 registros) y bibliotecas de universidades (4 registros) (Tabla 14 y Gráfica 8).

Tabla 14

\begin{tabular}{|l|c|}
\hline \multicolumn{1}{|c|}{ Fuentes y recursos } & Frecuencia \\
\hline Internet & 25 \\
\hline Diccionarios inglés-español & 25 \\
\hline Estudiantes y profesores & 20 \\
\hline Arqueólogos y otros profesionales & 18 \\
\hline Fábricas de tequila & 15 \\
\hline Colegas agricultores & 14 \\
\hline Fabricantes de artesanías & 12 \\
\hline Fabricantes de tequila & 12 \\
\hline Eventos de la región & 10 \\
\hline Bibliotecas públicas & 8 \\
\hline Bibliotecas de universidades & 4 \\
\hline
\end{tabular}

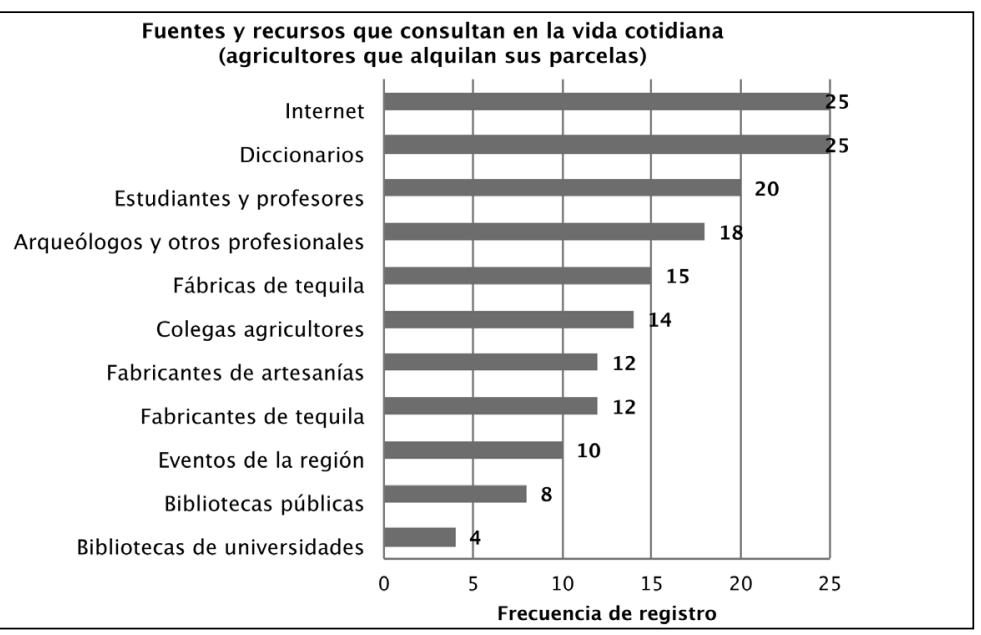




\section{Conclusiones}

Actualmente existe una marcada diferencia social, económica, laboral y cultural entre los diferentes grupos de agricultores de agave azul de Tequila, Jalisco, particularmente entre aquellos que fueron seleccionados para esta investigación: agricultores independientes y agricultores que alquilan sus parcelas.

Por un lado, encontramos a los agricultores independientes, quienes dadas sus amplias extensiones de tierra de cultivo y su capacidad para explotarlas no sólo compiten con las grandes casas tequileras, sino además en muchos casos se han convertido en sus únicos y principales distribuidores de materia prima, lo cual, como es de imaginarse, no sólo les ha generado fuertes ingresos económicos con el consiguiente aumento en su poder adquisitivo, sino también los ha llevado a realizar cambios considerables en su estilo de vida, estatus social, idiosincrasia y proyección futura.

Por otro lado, y en franco contraste con los anteriores, se encuentran aquellos agricultores que alquilan sus parcelas, quienes al no contar con amplios territorios de cultivo ni con la capacidad económica e industrial para explotarlos - situación que se combinó con los cambios propiciados por el boom turístico del municipio causado por las declaratorias de Pueblo Mágico y patrimonio de la humanidad - tuvieron que abandonar (en forma parcial o total) el oficio para desempeñar otros y poder subsistir. Esto no sólo los ha alejado de su labor ancestral, sino también ha transformado su estilo de vida, idiosincrasia, nivel social y aspiraciones futuras y, al igual que sucedió con los agricultores independientes, afectó sus necesidades de información y comportamiento informativo.

En el caso de los agricultores independientes resulta evidente que la mayoría de sus necesidades de información giran en torno a la adquisición de conocimientos y técnicas que les ayuden a mejorar los procesos productivos del agave, así como en la ampliación y fortalecimiento de sus tierras de cultivo desde el punto de vista agropecuario. En ese sentido, las fuentes y recursos a los que acuden están relacionados directamente con dichas necesidades, es decir, con todas aquellas personas, manuales o instituciones - fuentes secundarias y terciarias - involucradas en su ramo que puedan ayudarlos.

Para los segundos, incorporarse a sus nuevos oficios así como a su nuevo estatus social generó otras necesidades de información independientes de las que pudieran tener como agricultores. Por ejemplo, en los casos de quienes se incorporaron al sector turístico, el avance en los créditos de los cursos de acreditación propiciaba el surgimiento de nuevas necesidades de información. 
De estos hechos se desprende que al generarse dichas necesidades de información y su consiguiente satisfacción también se forjó en los agricultores un cúmulo de conocimientos nuevos, los cuales les ayudaron a paliar de mejor forma el proceso de adaptación a su nuevo entorno, estilo de vida e idiosincrasia, entre otros aspectos.

Asimismo, en cuanto a las fuentes y recursos que consultan, si bien es cierto que en algunos casos éstas corresponden al rubro de las fuentes secundarias - como diccionarios-, también existen muchas otras que son de primera mano - libros y bibliotecas-, lo cual favorece que la información que se obtiene de estas últimas sea mucho más confiable.

Finalmente, se puede inferir que las necesidades de información que surgen en ambos tipos de agricultores están determinadas, en gran medida, por el contexto social, económico y cultural que los rodea, con el cual tienen que interactuar y adaptarse para alcanzar un pleno desarrollo en todos los aspectos de su vida.

\section{BibLIOgRAFÍA}

Aina, L. 1985. "Information needs and information seeking involvement of farmers in six rural communities in Nigeria". Quarterly bulletin of international association of agricultural libraries and documentalist 30:35-40.

Álvarez, J. R. 1969. Jalisco: nueve ensayos. México: Ediciones Tlacuilo.

Bautista-Justo, M. et al. 2001. "El Agave Tequilana Weber y la producción de tequila”. Acta Universitaria 11 (2): 26-30.

Calva González, J. 2004. Las necesidades de información: fundamentos teóricos y métodos. México: UNAM.

Colunga, P. et al. 2007. En lo ancestral bay futuro: del tequila a los mezcales y otros agaves. México: CICY, Conacyt, Conabio, Semarnat, INE.

Consejo Regulador del Tequila.s. a.a. Estadísticas: Producción total de Tequila y Tequila $100 \%$ de agave. Disponible en http://www.crt. org.mx/EstadisticasCRTweb/ [Fecha de consulta: 30 de octubre de 2013].

- s. a.b. Estadísticas: Consumo de agave para Tequila y Tequila $100 \%$ de agave. Disponible en http://www.crt.org.mx/EstadisticasCRTweb/ [Fecha de consulta: 30 de octubre de 2013].

Cruz, A. 2012. "Bajo porcentaje de jornaleros agrícolas capacitados en manejo de pesticidas". La Jornada, 14 de septiembre, 50.

Dansac, Y. 2012. "Conceptualizaciones nativas y etnoconocimientos sobre vestigios prehispánicos en el folclore rural. Notas de la exploración del patrimonio etnológico de Teochitlán (México)”. Apuntes 25 (1): 115-125. 
Dávalos, I. 2012. "Paisaje agavero: creado por el hombre, amenazado por él mismo". Milenio Guadalajara, 9 de abril.

García, J. 1997. Estudio del cultivo del maguey tequilero, Agave Tequilana Weber y su industrialización en la región centro del estado de Jalisco, tesis, Ingeniería en Agronomía, Universidad Autónoma de Chapingo.

Gerritsen, P. y J. Morales. 2012. "La maldición del oro azul”. La Jornada del campo 53, 18 de febrero. Disponible en http://www.jorna da.unam.mx/2012/02/18/cam-oro.html [Fecha de consulta: 16 de agosto de 2012].

Gómez Arriola, I. 2006. "Patrimonio mundial: el paisaje agavero y las antiguas instalaciones industriales de Tequila". Patrimonio cultural y turismo 15. Cuadernos: itinerarios culturales y rutas del patrimonio. México: CONACULTA, 103-117.

_ 2009. "El plan de manejo para el paisaje agavero y las antiguas instalaciones industriales de Tequila: el patrimonio cultural como detonador del desarrollo regional, antecedentes, compromisos y retos". Apuntes 22 (2): 124-141.

González, C. 2003. "En las líneas del tiempo: el tequila. Cápsula 52”. Radio Red. Grupo Radio Centro, 12 de julio. Disponible en http:// radiocentro.com.mx/grc/redam.nsf/vwALL/MALZ-SPFSDN [Fecha de consulta: 23 de octubre de 2010].

González, L. 2010. Modelo turístico sustentable para el municipio de Tequila, Jalisco, México: una perspectiva del desarrollo local, tesis, Universidad de Guadalajara. Centro Universitario de Arte, Arquitectura y Diseño.

González, L. 2011. Turismo y desarrollo local en el paisaje agavero: una mirada al pueblo mágico de Tequila. México: Editorial Académica Española.

—_ y C. Marmolejo. 2011. "El medio sustentable para la actividad turística del municipio de Tequila, Jalisco”. Entorno 5 (11): 95-102.

Hernández, J. 2005. Chiapanecos en los campos agaveros. Notas de campo sobre el racismo alteño. Seminario de estudios regionales. México: Centro Universitario de los Altos, Universidad de Guadalajara.

— 2006. "Las vinazas del tequila: nuevos usos, viejas prácticas en el tratamiento de las aguas residuales del tequila en los Altos de Jalisco". Cuadernos de los Altos 3: 103-118.

_ 2007. "Más tradicional que el agave: la organización social de los agaveros alteños”. Libro Técnico 4: 1-89.

_ 2009. "Tequila: centro mágico, pueblo tradicional, ¿patrimonialización o privatización?” Andamios 6 (12): 41-67.

2011. "Encontrar el norte en los Altos de Jalisco. La migración de jornaleros chiapanecos a los campos agaveros". Balance y perspectivas del campo mexicano: a más de una década del TLCAN y del movimiento zapatista. Tomo III. Migraciones y movilidad laboral. México: UNAM, 223-247. 
Hernández, J. 2011. "Los paisajes agaveros y sus transformaciones culturales: expansión, intensificación y estetización”. Entre regiones, historia, sociedad y cultura 1: 111-132.

2012. “¿El paisaje o los paisajes agaveros?” Tecnoagave. Disponible en http://www.tecnoagave.mx/sitio/index.php/es/reportajes/ 133-el-paisaje-o-los-paisaes-agaveros [Fecha de consulta: 24 de octubre de 2014].

- et al. 2010. Patrimonio y cultura en América Latina: nuevas vinculaciones con el estado, el mercado, el turismo y sus perspectivas actuales. México: Universidad de Guadalajara.

Hernández López, José de J. 2008. “Tequila: pueblo mágico. De pueblo rural a desarrollo turístico". Historia regional y local. Las ciudades, su bistoria y su proyección en la región, t. III. México: Universidad de Guadalajara. Centro Universitario de los Altos, 157-185.

Herrera, L. 2011. El sistema de producción de Agave Tequilana Weber variedad azul y el desarrollo local en Tequila, Jalisco, tesis, Colegio de Posgraduados.

IFLA. 2010. Grupo de interés de las bibliotecas de agricultura. Disponible en http://www.ifla.org//files/hg/annual-conference/ifla76/ calls-for-papers/agricultura-libes.pdf [Fecha de consulta: 9 de junio de 2010].

Instituto Nacional de Estadística y Geografía. s. a. Información nacional por entidad federativa: Tequila, Jalisco. Disponible en http:// www.inegi.org.mx/default.aspx [Fecha de consulta: 30 de agosto de 2012].

López, A. 2002. "Multiplican el agave”. El Universal, 22 de noviembre, Estilos. Disponible en http://www.eluniversal.com.mx/estilos/24 640.html [Fecha de consulta: 20 de octubre de 2014].

Manzanilla, L. y L. López. 2001. Historia antigua de México. México: INHA, UNAM, Porrúa.

Molina, T. 2008. "Cedió México a EU control sobre el tequila". La Jornada, 24 de marzo, contraportada.

_ 2008. "El auge del tequila propició una migración por relevos". La Jornada, 24 de marzo, 16.

_ 2008. "El tequila es el licor con mayor índice de crecimiento en el consumo de Estados Unidos”. La Jornada, 24 de marzo, 17.

_ 2008. "En materia de tequila a granel, la ley es perversa; sólo se refiere a territorio nacional”. La Jornada, 24 de marzo, 19.

Nason, L. 2007. "The farmer in the library: information needs of farmers and how the rural public library can fulfill them". Rural Libraries 27 (2): 19-45.

Palapa, F. y J. Partida. 2006. "La región tequilera, patrimonio de la humanidad". La Jornada, 13 de julio, Sociedad y justicia. Disponible en http://www.jornada.unam.mx/2006/07/13/index.php?sec tion $=$ sociedad $\&$ article $=048 \mathrm{n} 1 \mathrm{soc}[$ Fecha de consulta: 20 de octubre de 2014]. 
Paredes, R. 2012. "Los desafíos del paisaje agavero, patrimonio de la humanidad". Incubarte. Disponible en http://incubarte.mx/blog/ los-desafios-del-paisaje-agavero-patrimonio-de-la-humanidad/ [Fecha de consulta: 16 de agosto de 2012].

Parsons, J. 2012. "Los agaves en la economía tradicional”. La Jornada del campo 53, 18 de febrero. Disponible en http://www.jornada. unam.mx/2012/02/18/cam-economia.html [Fecha de consulta: 16 de agosto de 2012].

Partida, J. 2012. "Productores de agave esperan nuevo auge". La Jornada, 21 de mayo, 28.

Pérez, J. y J. del Real. 2007. "Conocimiento y prácticas agronómicas para la producción de Agave Tequilana Weber, en la zona de denominación de origen del tequila". Libro Técnico 4: 1-89.

Ramírez, C. 2009. Necesidades de Información en comunidades indígenas: el caso de la comunidad Tepehua. México: UNAM, CUIB.

Rodríguez, J. y H. Hernández. 2006. "Plan de manejo”, en Patrimonio cultural y turismo 15. Cuadernos: itinerarios culturales y rutas del patrimonio. México: CONACULTA, 119-134.

Ruiz-Corral, J., E. Pimienta-Barrios y J. Zañudo. 2011. "Regiones térmicas óptimas y marginales para el consumo de Agave Tequilana Weber". Acta Universitaria 11 (2): 41-53.

Hernández López, José de Jesús. 2013. "De pueblo huertero a pueblo tequilero", en Paisaje y creación de valor. La transformación de los paisajes culturales del agave y del tequila. Michoacán: El Colegio de Michoacán/Fideicomiso "Felipe Teixidor y Monserrat Alfau de Teixidor", 95-115.

Sistema de Información Estadística y Geográfica de Jalisco. 2012. Tequila 2012: diagnóstico del municipio. México.

Soltero, F. 2006. "Relato de una candidatura exitosa", en Patrimonio cultural y turismo 15. Cuadernos: itinerarios culturales y rutas del patrimonio. México: Conaculta, 136-143.

Valenzuela, A. 2006. "Agave azul: historia por venir", en Patrimonio cultural y turismo 15. Cuadernos: itinerarios culturales y rutas del patrimonio. México: Conaculta, 145-157.

_ 2007. "Diagnóstico del sistema de producción ejidal de Agave Tequilana Weber, variedad azul en la región de origen: 20 años de expansión tequilera", en Primer Seminario Internacional del Tequila: ambiente, cultura y sociedad. México: Universidad de Guadalajara, 11-28.

—_ y S. Gaytán. 2009. "La expansión tequilera y las mujeres en la industria: del símbolo al testimonio". Ensayos: sociedades rurales, producción y medio ambiente 9 (18): 167-195.

Valenzuela, A. e I. López. 2010. "Las insustituibles fibras de agave para las sogas finas de charro". La Jornada, La Jornada en la Ciencia, 20 de julio. Disponible en: http://ciencias.jornada.com.mx/inves tigacion/ciencias-quimicas-y-de-la-vida/investigacion/las-insusti tuibles-fibras-de-agave-para-las 
Villalvazo, A. 1986. El cultivo del mezcal (Agave Tequilana Weber) en la región de Tequila, Jalisco, tesis, Universidad Autónoma de Chapingo.

Weitlander, R. y M. Olivera de Vázquez. 1969. Los grupos indígenas del norte de Oaxaca. México: Instituto Nacional de Antropología e Historia.

Anexo

Instrumento para entrevista (cuestionario) *

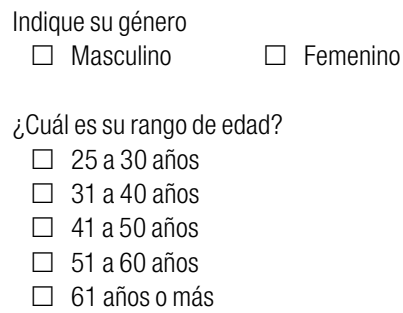

Indique cuál es su lugar de origen (nacimiento)

Indique cuál es su nivel de estudios
$\square$ Primaria
$\square$ Secundaria
$\square$ Bachillerato
Licenciatura

Realiza algún otro tipo de actividad económicamente remunerada además del cultivo de agave azul, (en caso afirmativo indique cuál)

Perfil informativo como agricultores

Comúnmente ¿qué tipo de información necesita para el desempeño de sus actividades como agricultor de agave azul? (señale en orden de preferencia del 1 al 10).

Comúnmente ¿a qué tipo de fuentes y/o recursos de información acude para satisfacer las anteriores necesidades de información? (señale en orden de preferencia del 1 al 10).

* Cabe señalar que dentro del cuestionario no se solicitó a los entrevistados indicar el tipo de agricultor que se es por razones de empatía con ellos. 
Perfil informativo dentro de su vida cotidiana o en el desempeño de otras labores aparte del cultivo de agave azul

Comúnmente ¿qué tipo de información necesita en el transcurso de su vida cotidiana o en el desempeño de otro oficio y/o profesión diferente al cultivo de agave azul? (señale en orden de preferencia del 1 al 10).

Comúnmente ¿a qué tipo de fuentes y/o recursos de información acude para satisfacer las anteriores necesidades de información que requiere en su vida cotidiana o en el desempeño de otro oficio y/o profesión diferente al cultivo de agave azul? (señale en orden de preferencia del 1 al 10).

Para citar este artículo:

Sánchez Soto, Armando. 2016. "Necesidades de información y comportamiento informativo de los agricultores de agave azul de Tequila, Jalisco: un estudio de caso.” Investigación Bibliotecológica: Archivonomía, Bibliotecología e Información 69: 143-178. http:// dx.doi.org/10.1016/j.ibbai.2016.04.016 